\title{
TRANSPORTATION SUSTAINABILITY INDEX FOR TABUK CITY IN SAUDI ARABIA: AN ANALYTIC HIERARCHY PROCESS
}

\author{
Attiyah M. Al-Atawi ${ }^{1}$, Ravindra Kumar ${ }^{2}$, Wafaa Saleh ${ }^{3}$ \\ ${ }^{1}$ Dept of Civil Engineering, University of Tabuk, Saudi Arabia \\ ${ }^{2,3}$ Transport Research Institute, Edinburgh Napier University, United Kingdom
}

Submitted 4 July 2014; resubmitted 18 September 2014; accepted 24 October 2014;

first published online 13 July 2015

\begin{abstract}
A sustainable transport strategies for Tabuk City in the Saudi Arabia has been developed using the Analytical Hierarchy Process (AHP) using travel data collected from Tabuk City. A number of transport policies and strategies have been tested for inclusion in the developed system. The top five strategies which were ranked highest amongst these by the respondents are policies that are targeting: clean environment, altering travel behaviour, shifting to more sustainable modes of transport, charging motorists for entering the city centre and charging motorists to enter the city if the revenue raised was spent on tackling environmental pollution caused by transport. The population have been classified according to gender, age, income and family structure groups. The strategy of promoting clean environment policies were high priority while for example, charging motorists to enter the city if the revenue raised was spent on tackling environmental pollution policies were not popular for any group. Priority ranking of transport sustainability at pre- and post-implementation stages of the transportation measure are important to provide recommendations for implementation. The strength of this approach is mainly in its ability to perform decision making under limited, heterogeneous data coming from multiple stakeholders which is presented in terms of different types of user group in our case study. This research can be further enhanced by testing further population groups and increasing the sample size.
\end{abstract}

Keywords: AHP method; sustainable transport; transport management; environmental impact.

\section{Introduction}

Recent growth in transportation activities and population in Saudi Arabia has resulted in increasing demand on fuels. The increasing population of Saudi Arabia along with the shift of the population to urban agglomerations will increase environmental concerns related to the transportation sector (Rahman, Al-Ahmadi 2011). The continuing growth of vehicle fleets and fuel consumption will subsequently increase the associated pollutant emissions and greenhouse gas emissions (EIA 2014).

The problem of vehicle related air pollution in Saudi Arabia is of primary concern because of severe climatic conditions, which accelerate the exhaust, evaporative and refuelling emissions of pollutants into the atmosphere. Moreover, the existing cars being used are not equipped with effective catalytic converters due to the presence of lead in the gasoline that poisons the catalysts present in the converters. The number of vehicles in Saudi Arabia is also increasing due to the rapid economic growth and these increases are translated into increased domestic consumption of gasoline (Rahman, Al-Ahmadi 2011).

The recent and past travel patterns show that the growing mobility needs and the simultaneous decline in public transportation use will no doubt lead to increases in congestion and worsening air quality. To meet the growing mobility needs on such a massive scale, several cities are considering various types of policies to manage the demand for travel which are appropriate to travel and traffic conditions for each city.

Saudi Arabia is an Islamic Kingdom where most Saudis practice Islamic religion and beliefs that are reflected in all aspects of their public and private lives including social and economic. The advent of oil in this country has been of primary importance for the past century and currently largest reservoir of petroleum in world. Oil revenues have been used to develop a vast network of infrastructure across the wide desert. However, challenges still remain as Saudi Arabia carefully treads the twenty-first century with hopes for sustainable transportation systems. This is especially true in Tabuk 
City as one of the largest and rapidly growing cities in the Saudi Arabia. Tabuk is situated in the north of the country and is strategically important for its role as the gateway to the Mediterranean countries. Its population is about 0.5 million with a rate annual growth of $2.5 \%$. Tabuk City is an example of a typical Saudi city that is essentially car dependent, with a car ownership rate of about 1.8 cars/household. Urban density of Tabuk is very low (100 person/hectare) (Al-Atawi, Saleh 2014). Such patterns of car ownership and urban development as well as the less developed public transportation systems have all contributed to the tremendous environmental, social and economic pressures on transport planners to work up a sustainable transportation system. In order to develop a successful sustainable transport system, the citizens' preferences and opinions must be taken into considerations.

Using Analytic Hierarchy Process (AHP) as a supporting tool for decision making has been gaining a better insight in complex decision problems. It needs a structure the problem as a hierarchy, it forces to think through the problem, consider possible decision criteria and select the most significant criteria with respect to the decision objective. Using pairwise comparisons helps to discover and correct logical inconsistencies. The method also allows to 'translate' subjective opinions, such as preferences or feelings, into measurable numeric relations. AHP helps to makes decisions in a more rational way and to make them more transparent and better understandable (Goepel 2014).

Appreciation and the use of power of AHP methods are many but very few deals with criteria in complex social economic travel behaviour and transportation sustainability of Saudi Arabia where female are not allowed to drive and cheapest oil price in world (Al-Atawi, Saleh 2014). In this paper, an AHP based framework for a sustainable transport system has been developed taking into account the attitudes and preferences of the users of the transportation system of Tabuk City in the Saudi Arabia.

\section{Previous Works on AHP Approach for Sustainable Transportation}

The AHP belongs to the Multi-Criteria Decision Making (MCDM) methods group. The AHP is a MCDM-supporting method in discrete environments (Saaty 1977, 1980; Tao, Hung 2003). It aims to decompose a complex decision problem in a hierarchy of smaller constituent sub-problems. Determining the most preferred alternative from a set of products is a decision problem where the top level of the hierarchy represents the individual product. The detailed has been explained below, for details see Triantaphyllou and Mann (1995). The structure of the typical decision problem considered in this paper consists of a number, say $M$, of alternatives and a number, say $N$, of decision criteria. Each alternative can be evaluated in terms of the decision criteria and the relative importance (or weight) of each criterion can be estimated as well. Let $a_{i j}(i=1,2,3, \ldots, M$ and $j=1,2,3$,
..., $N$ ) denote the performance value of the $i$-th alternative (i.e., $A_{i}$ ) in terms of the $j$-th criterion (i.e., $C_{j}$ ). Also denote as $W_{j}$ the weight of the criterion $C_{j}$. Then, the core of the typical MCDM problem can be represented by the given decision matrix.

MCDM plays a critical role in many real life problems. It is not an exaggeration to argue that almost any local or federal government, industry, or business activity involves, in one way or the other, the evaluation of a set of alternatives in terms of a set of decision criteria. Very often, these criteria are conflicting with each other. Even more often, the pertinent data are very expensive to collect (Triantaphyllou, Mann 1995). AHP is one of the method of MCDM.

AHP and its use of pairwise comparisons has inspired the creation of many other decision-making methods due to it wide acceptance. Besides its wide acceptance, it also created some considerable criticism; both for theoretical and for practical reasons. Since the early days, it became apparent that there are some problems with the way pairwise comparisons are used and the way the AHP evaluates alternatives. Belton and Gear (1983) observed that the AHP may reverse the ranking of the alternatives when an alternative identical to one of the already existing alternatives is introduced. In order to overcome this deficiency, Belton and Gear (1983) proposed that each column of the AHP decision matrix to be divided by the maximum entry of that column. Thus, they introduced a variant of the original AHP, called the revised-AHP.

Later, Saaty (2000) accepted the previous variant of the AHP and now it is called the Ideal Mode AHP. Besides the revised-AHP, other authors also introduced other variants of the original AHP. However, the AHP (in the original or in the ideal mode) is the most widely accepted method and is considered by many as the most reliable MCDM method.

Yedla and Shrestha (2007) applied AHP to prioritize urban transport. Their study compared different group aggregation methods adopted in AHP by testing them against social choice axioms with a case study of Delhi transport system.

Awasthi and Chauhan (2011) evaluated sustainable transport measures and propose a hybrid approach based on AHP and D-S theory. In their approach, AHP was used to evaluate criteria for assessing the performance of transportation measures. Data on transportation measure performance was collected from multiple information sources and aggregated using D-S theory to generate a transport sustainability index. Transport sustainability index was computed at two stages: preand post-test stages of the transportation measure and assessment of the impacts of the transportation measure on the city sustainability was done by observing the difference between the values at the pre- and the post-test stages to assess whether the impact of the transportation measure on city sustainability is positive or negative and develop recommendations for the application on the transportation measure which was car sharing. 
Castillo and Pitfield (2010) used Evaluative and Logical Approach to Sustainable Transport Indicator Compilation (ELASTIC) a methodological framework for identifying and selecting sustainable transport indicators using AHP.

Rossi et al. (2013) made a comparison of fuzzybased and AHP methods in sustainability evaluation: a case of traffic pollution-reducing policies for e-urban transit service. A multi-dimensional vision of sustainable mobility has been accepted as a reference point for stakeholders and experts; it finds a significant representation in the concept of the 'three pillars of sustainability', which examines the idea of sustainability from a three-dimensional perspective: social, economic and environmental. In the AHP case, the experts were asked to compile pair-wise comparison matrices using verbal judgements. The weights associated with each of them were calculated by expert choice. Indicators used for evaluation were social (community and transit) economic (operating cost and user cost) and environment (change in $\mathrm{CO}$ emission, reduction in fuel cost).

Paz et al. (2013) developed Transportation Sustainability Index (TSI) and Transportation System Performance Index (TSPI) and measured direct effects of policy options on performance measures in terms of pricing, technology fuel and Innovative vehicle Technologies and applied AHP and fuzzy logic and found that current transportation growth has negative impact on environment.

Quddus et al. (2014) developed a framework to assess the sustainability of transportation systems based on AHP. His major concern in the assessment were:

- the safety issues for all users;

- the system's efficiency in providing accessibility and mobility;

- the potential of the transportation systems to enhance economic productivity and social justice;

- limiting the negative impact on the natural environment.

Saaty (1995) explored five examples of applications of the AHP are made to illustrate the different uses of this ratio scale MCDM method in transportation. He included a commuter route selection hierarchy, a best mix of routes to Pittsburgh's new International Airport, a benefits/costs hierarchy to choose the best mode to cross a river, a planning hierarchy for a transport system and a simple dependence with feedback cycle to choose a car when criteria depend on the alternatives.

Kara and Köne (2012) used the analytic hierarchy process (AHP) approach for assessment of regional environmental sustainability. They assessed environmental sustainability at different spatial scales, two hierarchy trees; in other words, two models were developed. The only difference between the two models was the sample (or the alternatives). Although both models cover the same geographical area, first model focuses on subregions while the second model deals with the provinces of these sub-regions.

Several researches have carried out investigation on the transportation sustainability issue using AHP; however most of them were region-specific (Kara, Köne 2012; Castillo, Pitfield 2010; Awasthi, Chauhan 2011) or policy specific (Quddus et al. 2014; Saaty 1995; Paz et al. 2013; Rossi et al. 2013; Yedla, Shrestha 2007; Alonso, Lamata 2006). No previous work was carried out using Middle Eastern case studies where the social, cultural and economic conditions are completely different. In this paper, an AHP has been developed for the Tabuk City in the Saudi Arabia.

\section{The Proposed AHP for Tabuk City: a Case Study}

In this section structuring the criteria hierarchy and application of AHP frame work of sustainable transportation system index for Tabuk City is discussed as follows.

\subsection{Structuring the Criteria Hierarchy}

An approach based on pairwise comparisons which was proposed by Saaty (1980) has long attracted the interest of many researchers. Pairwise comparisons are used to determine the relative importance of each alternative in terms of each criterion. In this approach the decisionmaker has to express his opinion about the value of one single pairwise comparison at a time. Usually, the decision-maker has to choose his answer among 10-17 discrete choices. Each choice is a linguistic phrase. For instance, when system $A$ is compared to system $B$, then the decision-maker has determined that system $A$ is between to be classified as 'essentially more important' and 'demonstrated more important' than system $B$ (Table 1). Thus, the corresponding comparison assumes the value of 6. A similar interpretation is true for the rest of the entries.

The next step is to extract the relative importance implied by the previous comparisons. That is, how important are the three alternatives when they are considered in terms of the hardware expandability criterion? Saaty asserts that to answer this question one has to estimate the right principal Eigen vector of the previous matrix.). An evaluation of the Eigen value approach can be found in researches by Triantaphyllou and Mann (1995), Salo and Hämäläinen (1997). One of the most practical issues in the AHP methodology is that it allows for slightly non-consistent pairwise comparisons. For example, in the AHP the pairwise comparisons in a judgment matrix are considered to be adequately consistent if the corresponding Consistency Ratio (CR) is less than 10\% (Saaty 1980). The CR coefficient is calculated as follows. First the Consistency Index (CI) needs to be estimated. This is done by adding the columns in the judgment matrix and multiply the resulting vector by the vector of priorities (i.e., the approximated Eigen vector) obtained earlier. This yields an approximation of the maximum Eigen value, denoted by $\lambda_{\max }$. Then, the CI value is calculated by using the formula: $C I=\frac{\lambda_{\max }-n}{n-1}$. Next the consistency ratio $\mathrm{CR}$ is obtained by dividing the $\mathrm{CI}$ value by the Random Consistency Index (RCI) If the CR value is greater than 0.10 , then it is a good idea to study the problem further and re-evaluate the pairwise compari- 
Table 1. Scale of relative importance (according to Saaty 1980)

\begin{tabular}{lll}
\hline $\begin{array}{l}\text { Intensity of } \\
\text { importance }\end{array}$ & \multicolumn{1}{c}{ Definition } & Explanation \\
\hline 1 & Equal Importance & Two activities contribute equally to the objective \\
\hline 3 & Weak importance of one over another & $\begin{array}{l}\text { Experience and judgment slightly favour one } \\
\text { activity over another }\end{array}$ \\
\hline 5 & Essential or strong importance & $\begin{array}{l}\text { Experience and judgment strongly favour one } \\
\text { activity over another }\end{array}$ \\
\hline 9 & Demonstrated importance & $\begin{array}{l}\text { An activity is strongly favoured and its } \\
\text { dominance demonstrated in practice }\end{array}$ \\
\hline 2468 & Absolute importance & $\begin{array}{l}\text { The evidence favouring one activity over another } \\
\text { is of the highest possible order of affirmation }\end{array}$ \\
\hline $\begin{array}{l}\text { Reciprocals of } \\
\text { above nonzero }\end{array}$ & $\begin{array}{l}\text { If activity } i \text { has one of the above nonzero numbers } \\
\text { assigned to it when compared with activity } j, \\
\text { then } j \text { has the reciprocal value when compared with } i\end{array}$ & When compromise is needed \\
\hline
\end{tabular}

sons (after the alternatives are compared with each other in terms of each one of the decision criteria and the individual) priority vectors are derived, the synthesis step is taken. The priority vectors become the columns of the decision matrix (not to be confused with the judgment matrices with the pairwise comparisons). The weights of importance of the criteria are also determined by using pairwise comparisons. Therefore, if a problem has $M$ alternatives and $N$ criteria, then the decision maker is required to construct $N$ judgment matrices (one for each criterion) of order $M \times M$ and one judgment matrix of order $N \times N$ (for the $N$ criteria). Finally, given a decision matrix the final priorities, denoted by $A_{A H P}^{i}$, of the alternatives in terms of all the criteria combined are determined according to the following Eq. (1):

$$
A_{A H P}^{i}=\sum_{j=1}^{N} a_{i j} W_{j}, \text { for } i=1,2,3, \ldots, M .
$$

The first step in the AHP is the estimation of the pertinent data.

Recall that in the case of the ideal mode AHP the columns of the decision matrix are normalized by dividing by the largest entry in each column. The numerical data for this example were adapted from an example given in (Saaty 1986).

\subsection{Application of AHP Framework of Sustainable Transportation System Index for Tabuk City}

Application of AHP frame work is implemented through Data Collection of Travel Behaviour Survey and detail development of AHP Frame work which is discussed in details.

\subsubsection{Data Collection through Travel Behaviour Survey}

The objective of the survey has been to gather a large amount of data on socio economic status, travel patterns, mode choice, stated preferences on the various modes of travel, and the attitudes of a number of traffic and transport policies in Tabuk City of the Saudi Arabia.
In this research, a large data set has been collected and analysed from Tabuk City in the Saudi Arabia. The study was aimed at investigating the willingness of individuals to change their modes of transportation and what factor would instigate the decisions to change. This data has also been used to establish how sustainable the observed and reported travel patterns are within the city. Respondents' assessment of a number of traffic and transport policies have been reported and analysed. Finally, data was collected on socio-economic characteristics of the individuals and the households. In total, 1226 surveys were distributed throughout the Tabuk City, overall 516 completed surveys were returned which gave an overall response rate of $42.0 \%$ for the study as a whole. The questionnaires were distributed in different sectors in order to cover all workplaces in Tabuk City. This includes: health services, educational services, military sector, security sector, private and Tabuk municipality and water authority. The responses of the different population groups to transport policies have been used in this analysis.

\subsubsection{AHP Framework Development}

Ibeas et al. (2011) and Hull (2008) emphasised the importance of involving the citizen while developing policies and plans related to sustainable mobility. The citizens are the essential nucleus of any policy as the effects, either positive or negative, of a certain act are going to fall on them.

In the case of Tabuk City, the proposed AHP for the sustainable strategies is shown in Fig. 1. In this case the adopted process, includes three main stages:

1) policy identification: at this stage the relevant policies which affect sustainability have to be defined;

2) policy assessment: at this stage the assessment devise or scale are to be defined;

3) population groups: at this stage the population groups which are taking part in the assessment are to be defined. 


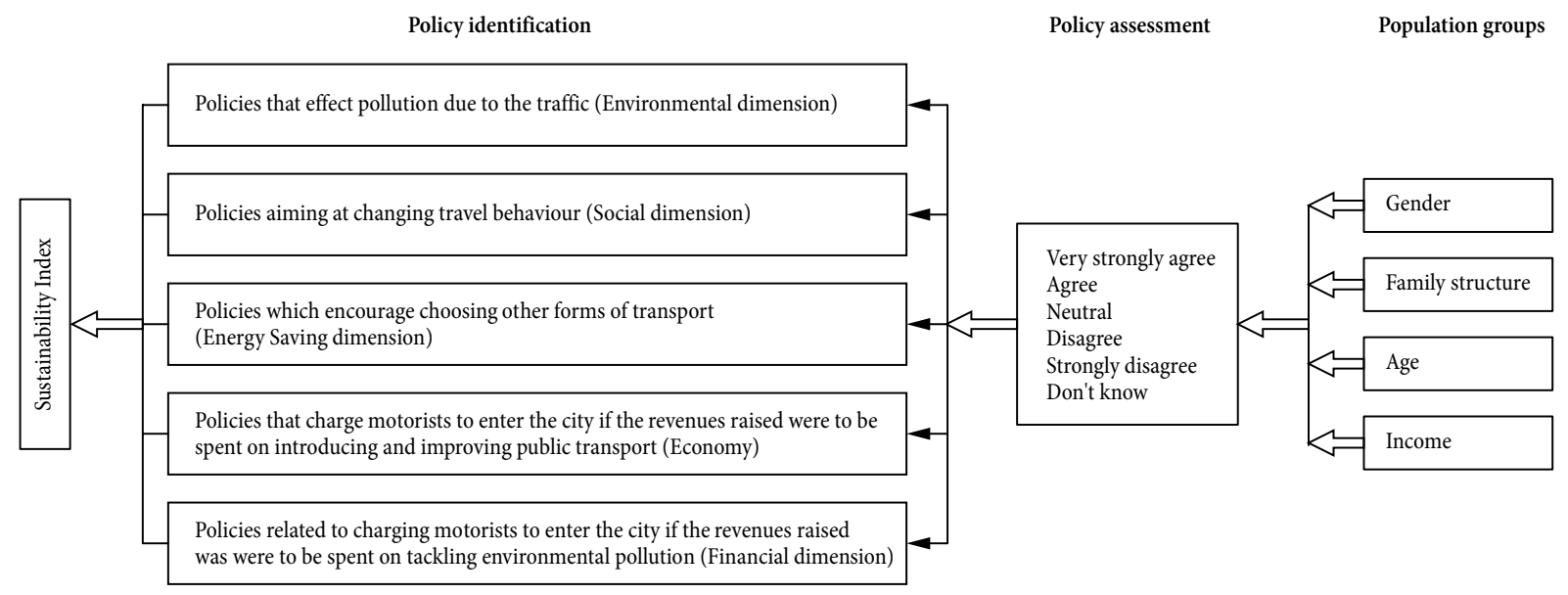

Fig. 1. The sustainable frame work AHP for Tabuk City

In the case of Tabuk City, the five relevant categories of policies which have been assessed:

- policies that affect pollution due to the traffic in the city.

- policies aiming at changing travel behaviour if public transport and pricing policies were introduced in Tabuk City.

- policies which encourage choosing other forms of transport rather than the car to travel to work if public transport modes were introduced in the city.

- policies that charge motorists to enter the city if the revenues raised were to be spent on introducing and improving public transport.

- policies related to charging motorists to enter the city if the revenues raised were to be spent on tackling environmental pollution (caused by transport); Fig. 1 present an overview of the process.

Secondly, the devise of policy assessment is assessed by the population groups on a five points scale ranging from 'strongly agree' to 'strongly disagree' as shown in Fig. 1. Lastly, four population groups are defined to take part in the assessment based on gender, family structure, age and income as presented in Fig. 1. Public participation in the process of developing any transport strategy not only strengthen and improves its outputs, affects the interests of society in general, and also enhances the image of the politicians. Therefore, this process could create great trust of the authorities and the spending of public resources. It will also improves issues of social equity and public acceptability of the strategies (Shiau 2012). Citizen involvement can therefore be seen as a strategic value which enriches the social process, and as a resource which qualifies or strengthens some parts of it, legitimizing it or making it more pertinent or effective (Ministerio de Planificación... 2005; Dyer, Wendell 1985; Rossi et al. 2013). Social involvement mainly operates in the immediate territorial and functional environment and is channelled through membership of a network of associations. The main objective is to achieve improved lifestyle conditions at both an individual and collective levels, and only when the people are well informed and feel they belong will agreement exist to move the community forward. The proposed AHP for the sustainable strategies is shown in Fig. 1.

\subsection{Example for Tabuk City}

In this case, as shown in Fig. 1, the process is decomposed into a predefined number of characteristics (attributes) on the second level and their corresponding levels on the third level as can be seen in Fig. 1. AHP estimates eliciting weights $w$ for each attribute and attribute level in order to explain individual behavior in choosing the preferred product. The relative importance or weight $w$ for attribute $A_{n}$ and level $L_{n . p}$, where: $n$ (1, $\ldots, N)$ is the number of attributes and $p(1, \ldots, P)$ is the number of levels, are obtained from pairwise comparisons.

As it is known from above that mathematically the method is based on the solution of an Eigen value problem. The results of the pair-wise comparisons are arranged in a matrix. The first (dominant) normalized right Eigen vector of the matrix gives the ratio scale (weighting), the Eigen-value determines the consistency ratio.

In this study same is used to set priorities from pairwise comparisons using the AHP with Eigen vector method. Input can be given for the number of criteria between 3 and 15 and a name for each criterion. Next a pairwise comparison can be done showing: which of the criteria in each pair is more important, and how many times more, on the 1 to 9 scale. The results can be calculated and get the resulting priorities, their ranking, and a consistency ratio CR (ideally $<10 \%$ ). Calculation can be done using the fundamental 1 to 9AHP ratio scale or the balanced scale (Goepel 2014).

In order to implement the AHP, a survey were carried out in Tabuk City to compare between different sustainable transport option (a) to (e) make two types of pairwise comparisons:

- a pairwise comparison of the levels within each attribute;

- a pairwise comparison of the attributes. 
First, the respondent has to indicate which of the two elements the respondent prefers. Then a six-point scale is used to measure the strength of this preference by means of verbal judgments as shown in Table 2 . From the answers provided, a matrix with the following structure is generated for each individual $k(1, . ., K)$ and is known as a Saaty's matrix.

Table 2. The AHP comparison scale

\begin{tabular}{cc}
\hline $\begin{array}{c}\text { Degree of importance rating } \\
\text { as per Saaty (1980) }\end{array}$ & $\begin{array}{c}\text { Definition of the scale } \\
\text { adopted in Tabuk City }\end{array}$ \\
\hline 9 & strongly agree \\
\hline 8 & agree \\
\hline 7 & neutral \\
\hline 6 & disagree \\
\hline 5 & strongly disagree \\
\hline 4 & don't know \\
\hline
\end{tabular}

\section{General Results and Discussions}

Four groups based on gender, family structure, age and income respondents have been defined as pairwise comparison for six different scale. Four hundred and sixteen respondents were chosen to form the decision groups. From those sample, the classification by gender was done. It was found that there were 66\% 'male' and
$34 \%$ 'female'. Data analysis were done in terms of family structure such head, wife, eldest son, daughter, son, and other. The proportion of family structure are as: $42.65 \%$ were 'head' ( $22.51 \%$ were 'wife', $11.61 \%$ were 'eldest son', $10.18 \%$ were 'daughter', $11.61 \%$ were 'son' and $1.4 \%$ were other. In terms of age groups, these were 15-20 (40\%), 21-25 (23.24\%), 26-30 (31.65\%), 31-35 (22.12\%), 36-40 (12.88\%), 41-45 (4.20\%), 46-50 (3.36\%), 51-55 (0.84\%), 56-60 (0.280\%). Data from household survey were also analysed in terms of different income level. Seven different income categories were classified. Their wages were measured in Saudi Riyals (SR) currency. It was observed the following proportion The households under SR 4000 (12.09\%), SR 4000-8000 (34.65\%), SR 800112000 (29.30\%), SR 12001-18000 (14.41\%), SR 1800125000 (5.34\%), SR 25001-30000 (1.16\%), and income level greater than SR 30000 (3.02\%).

The AHP application determined the criteria weights given by each groups (gender, family structure, age, and income) representative for different questionnaire of user perception on environment, social, energy, economy and finance policy for sustainable transportation policy option in Tabuk City. The criteria weights are listed in Table 3. From the index it is clear that the most important criteria by gender, family structure, income, age is effect of air pollution due to traffic because weight associated with is higher in each group.

Table 3. Weight of sustainable criteria using AHP process

\begin{tabular}{|c|c|c|c|c|c|c|c|c|c|c|c|}
\hline \multirow{3}{*}{ Groups } & \multirow{3}{*}{ Class } & \multicolumn{10}{|c|}{ Sustainability criteria } \\
\hline & & \multicolumn{2}{|c|}{ Environment (15 a) } & \multicolumn{2}{|c|}{ Social (16 a) } & \multicolumn{2}{|c|}{ Energy (16 b) } & \multicolumn{2}{|c|}{ Economy (17 d) } & \multicolumn{2}{|c|}{ Finance (17 f) } \\
\hline & & Weight & Value & Weight & Value & Weight & Value & Weight & Value & Weight & Value \\
\hline \multirow{2}{*}{ Gender } & male & 0.497 & 209 & 0.238 & 79 & 0.08 & 87 & 0.08 & 76 & 0.08 & 78 \\
\hline & female & 0.497 & 109 & 0.238 & 34 & 0.08 & 42 & 0.08 & 39 & 0.08 & 41 \\
\hline \multirow{6}{*}{ Family } & head & 0.497 & 138 & 0.238 & 45 & 0.08 & 60 & 0.08 & 46 & 0.08 & 42 \\
\hline & wife & 0.514 & 76 & 0.253 & 21 & 0.071 & 26 & 0.078 & 30 & 0.085 & 28 \\
\hline & eldest son & 0.514 & 37 & 0.239 & 18 & 0.079 & 16 & 0.086 & 19 & 0.082 & 17 \\
\hline & daughter & 0.525 & 33 & 0.239 & 13 & 0.09 & 18 & 0.670 & 10 & 0.078 & 13 \\
\hline & son & 0.525 & 34 & 0.239 & 16 & 0.09 & 15 & 0.670 & 12 & 0.078 & 15 \\
\hline & other & 0.507 & 4 & 0.223 & 2 & 0.094 & 6 & 0.086 & 2 & 0.090 & 2 \\
\hline \multirow{9}{*}{ Age } & $15-20$ & 0.498 & 6 & 0.253 & 2 & 0.079 & 2 & 0.080 & 2 & 0.090 & 2 \\
\hline & $21-25$ & 0.505 & 61 & 0.253 & 26 & 0.084 & 27 & 0.077 & 20 & 0.081 & 20 \\
\hline & $26-30$ & 0.505 & 86 & 0.253 & 19 & 0.084 & 39 & 0.077 & 25 & 0.081 & 32 \\
\hline & $31-35$ & 0.497 & 65 & 0.253 & 19 & 0.083 & 30 & 0.083 & 30 & 0.083 & 21 \\
\hline & $36-40$ & 0.517 & 35 & 0.205 & 17 & 0.101 & 14 & 0.084 & 9 & 0.093 & 16 \\
\hline & $41-45$ & 0.497 & 11 & 0.238 & 6 & 0.088 & 8 & 0.088 & 7 & 0.088 & 7 \\
\hline & $45-60$ & 0.499 & 9 & 0.204 & 3 & 0.099 & 5 & 0.099 & 4 & 0.099 & 3 \\
\hline & $51-55$ & 0.491 & 3 & 0.222 & 2 & 0.100 & 2 & 0.096 & 3 & 0.092 & 2 \\
\hline & $56-60$ & 0.482 & 1 & 0.253 & 1 & 0.089 & 1 & 0.092 & 1 & 0.085 & 1 \\
\hline \multirow{7}{*}{ Income } & $<4000$ & 0.497 & 33 & 0.238 & 19 & 0.088 & 20 & 0.088 & 14 & 0.088 & 18 \\
\hline & $4000-8000$ & 0.497 & 110 & 0.238 & 44 & 0.088 & 50 & 0.088 & 41 & 0.088 & 40 \\
\hline & $8001-12000$ & 0.497 & 97 & 0.238 & 39 & 0.088 & 39 & 0.088 & 38 & 0.088 & 36 \\
\hline & $12001-18000$ & 0.490 & 46 & 0.238 & 19 & 0.091 & 21 & 0.087 & 18 & 0.094 & 15 \\
\hline & $18001-25001$ & 0.498 & 16 & 0.220 & 7 & 0.093 & 8 & 0.093 & 9 & 0.093 & 13 \\
\hline & $25001-30000$ & 0.497 & 5 & 0.238 & 2 & 0.088 & 3 & 0.088 & 2 & 0.088 & 3 \\
\hline & $>30000$ & 0.525 & 12 & 0.239 & 4 & 0.09 & 3 & 0.067 & 3 & 0.078 & 4 \\
\hline
\end{tabular}




\section{Compute Sustainability Ranked Value (SRV) of Each Level According to the Classification of Sustainability Grade}

The CI value of sustainable transportation for environmental, social, economic and finance dimensions are shown in Figs 2-5 respectively. The composite (Figs 2-5): sustainability index for male and female for environment is compared. From the Fig. 2 it is clear that females are more concern on environmental issue than man whereas man are more concern on social issue of behaviour change due to transport policy and pricing. In family structure wife and daughter were more concerned on environmental issues.

Also higher income group above 30000 SR showed more composite index for environment issue due to transport. Whereas less than $4000 \mathrm{SR}$ income group shown more concern for social issues of behaviour changes due to introduction of transport policy and pricing (Fig. 5). Age group of 15-20 were highly sensitive to environment. Next age group of 45-60 and 31-35 shows higher concern of air pollution due to traffic. Age group 15-20 and 41-50 shows more concern on social

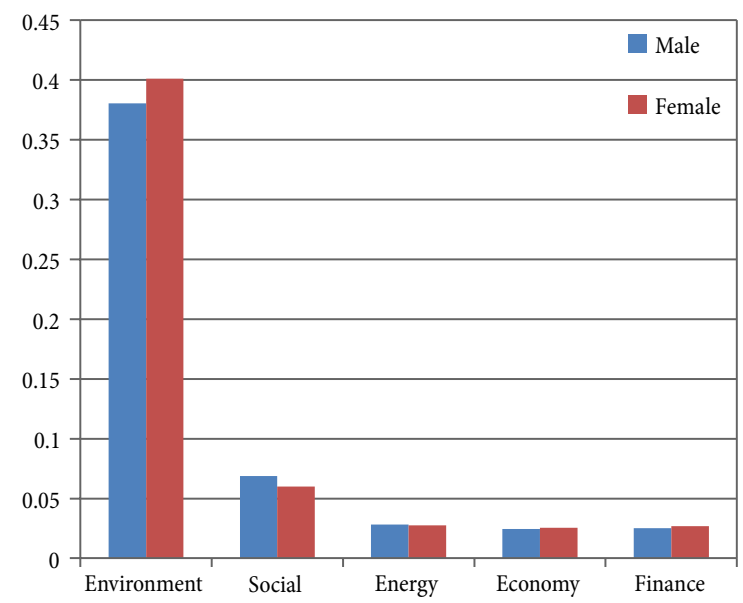

Fig. 2. Composite Index of level of sustainability from gender perspective

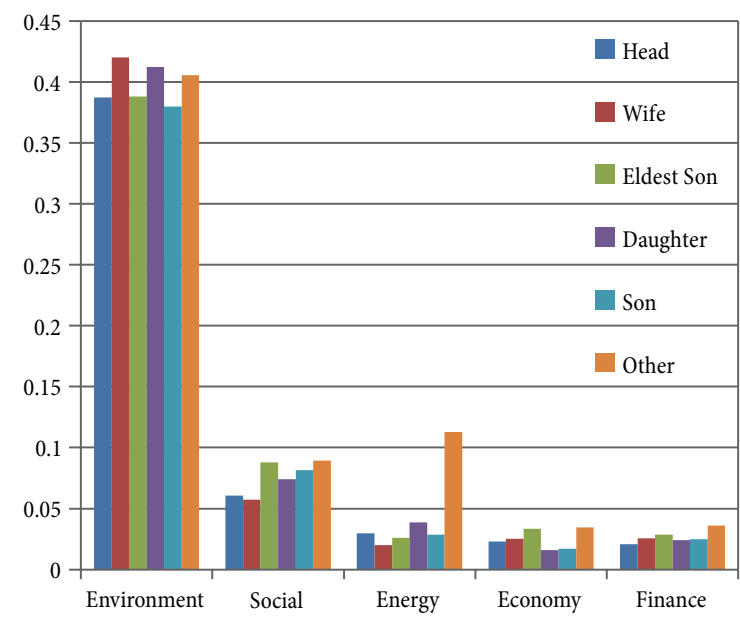

Fig. 3. Composite Index of level of sustainability from family perspective

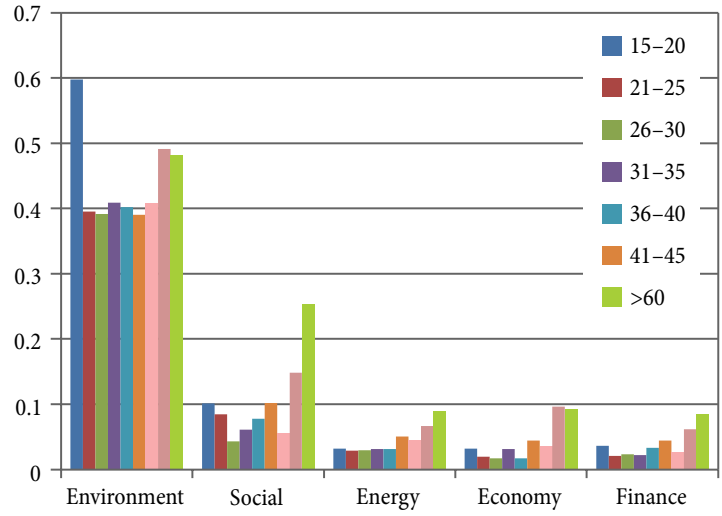

Fig. 4. Composite Index of level of sustainability from age perspective

issue of transport policies aiming at changing travel behaviour if public transport and pricing policies were introduced in Tabuk City (Fig. 4).

Income range greater than 30000 SR, 1800125000 SR and 8001-12000 SR shows more concern on environment transport policies that affect pollution due to the traffic in the city. Whereas income group falling less than 4000 SR shows more concern on social issue of transport policies aiming at changing travel behaviour if public transport and pricing policies and policies which encourage choosing other forms of transport rather than the car to travel to work if public transport modes were introduced in the city. It shows that low income categories are more preferring public transport mode helpful (Fig. 5).

Overall sustainable transportation development indicators in Tabuk City of the Saudi Arabia from the environmental dimension achieves the highest value from 0.3 to 0.6 for different categories of responded. Environment issue was highest among the younger. Whereas, this age group did not rate much to economy or finance, social issues of behaviour changes were found highest by different age group and strongest CI was for 41-60 age group in middle age category.

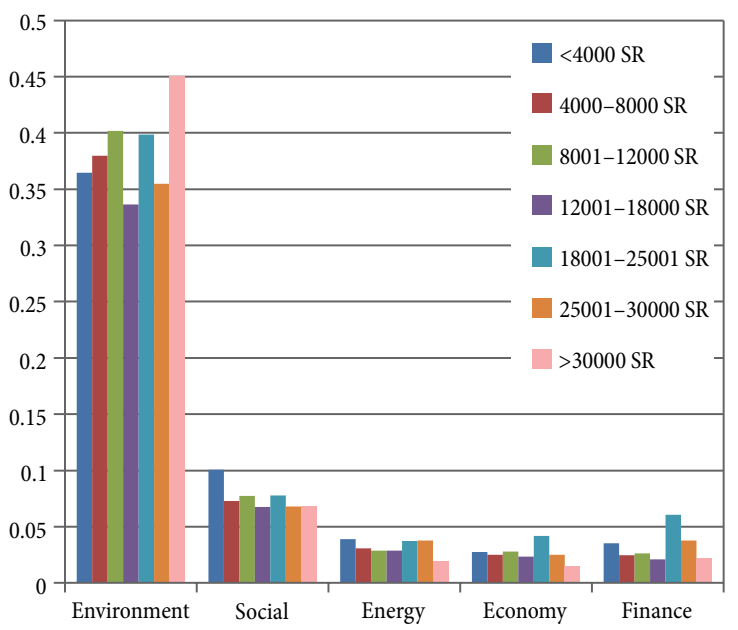

Fig. 5. Composite Index of level of sustainability from income perspective 


\section{Sustainability Compound Index (SCI) Assessment}

The SCI is the global utility for implementing the sustainable transport strategy $j$, and is expressed (Shiau 2012) as Eq. (2):

$$
S C I_{j}=\sum_{i=1}^{N} w_{i} \cdot u_{i},
$$

where: $w_{i}$ represents the weight of criterion $i$ and the utility under criterion $i$ is calculated using Eq. (3):

$$
u_{i}=\sum_{l=1}^{4} u\left(H_{l}\right) \cdot B P A\left(H_{l}\right) \text {, }
$$

where: $u_{i}$ is utility under criteria on obtained from the AHP; $u\left(H_{l}\right)$ is level of performance evaluation for this study, $l=4 ; B P A\left(H_{l}\right)$ is Basic Probability Assignment (BPA) for different level of evaluation which has been computed using BPMSG AHP Online System (Goepel 2014).

Taking the strategy $s$ for example environmental impact due to traffic, using Eq. (2), the SCI value is calculated as SCI (Gender) =0.391, SCI (Family) =0.399, $S C I($ Age $)=0.441$ and SCI $($ Income $)=0.384$.

Table 4 shows the priority ranking of sustainable transport strategies based on different groups such as gender, family structure, age, and income. All the five strategies evaluated by these groups on environment, social, economy and finance, promoting the use of sustainable transportation system in Tabuk City of the Saudi Arabia. Strategy of improving the environmental pollution due to traffic was ranked in the top by all groups. Environment was most sensitive and emergent view from people of different group.

The respondents were concerned to change in their travel behaviour due to transport policy and pricing social issue. Additionally, the respondents were concerned about choosing other forms of transport rather than their car to travel to work if public transport modes were introduced for energy saving. Also respondent were concerned with the strategies of charging motorists to enter the city if the revenue raised was spent on introducing and improving public transport in Tabuk City of the Saudi Arabia.

The results from Table 4 clearly shows that over solution for charging motorists to enter the city if the revenue raised was spent on tackling environmental pollution (caused by transport) was found better solution than revenue sued for public transport purpose. People have not like idea of public transport funding through congestion charging in the city.

\section{Conclusions}

This study evaluated sustainable transport strategies for Tabuk City in the Saudi Arabia using an AHP with travel data collected from the city. The top five strategies favoured by the interviewed sample include:

- clean environment;

- change in travel behaviour by using appropriate transport policies and strategies (social dimension);

- choosing other forms of transport than the private car to travel to work if public transport modes were introduced (energy saving dimension);

- charging motorists to enter the city if the revenue raised was spent on introducing and improving public transport (economy dimension);

- charging motorists to enter the city if the revenue raised was spent on tackling environmental pollution caused by transport (financial dimension).

The judgments of representatives from the population including distinct gender, age, income and family structure groups are however, different. The strategy of promoting clean environment policies were high priority while for example, charging motorists to enter the city if the revenue raised was spent on tackling environmental pollution policies were not popular for any group. Priority ranking of transport sustainability at preand post-implementation stages of the transportation measure are important to provide recommendations for implementation. The strength of the approach lies in its ability to perform decision making under limited,

\begin{tabular}{|c|c|c|c|c|c|c|c|}
\hline \multirow{2}{*}{ Strategies } & \multicolumn{5}{|c|}{ Average SCI } & \multirow{2}{*}{$\begin{array}{l}\text { Sum } \\
\text { total }\end{array}$} & \multirow{2}{*}{$\begin{array}{l}\text { Overall } \\
\text { priority } \\
\text { ranking }\end{array}$} \\
\hline & Gender & Family & Age & Income & Average & & \\
\hline To have clean environment & 0.391 & 0.399 & 0.441 & 0.384 & 0.404 & 2.019 & 1 \\
\hline $\begin{array}{l}\text { Change in travel behaviour due to transport policy and } \\
\text { pricing - Social Issue }\end{array}$ & 0.064 & 0.075 & 0.103 & 0.076 & 0.080 & 0.398 & 2 \\
\hline $\begin{array}{l}\text { Choosing other forms of transport rather than their } \\
\text { car to travel to work if public transport modes were } \\
\text { introduced - Energy Saving }\end{array}$ & 0.028 & 0.043 & 0.045 & 0.032 & 0.037 & 0.185 & 3 \\
\hline $\begin{array}{l}\text { Charging motorists to enter the city if the revenue raised } \\
\text { was spent on introducing and improving public } \\
\text { transport-Economy }\end{array}$ & 0.025 & 0.025 & 0.043 & 0.026 & 0.030 & 0.149 & 5 \\
\hline $\begin{array}{l}\text { Charging motorists to enter the city if the revenue raised } \\
\text { was spent on tackling environmental pollution (caused by } \\
\text { transport) - Finance }\end{array}$ & 0.026 & 0.027 & 0.039 & 0.033 & 0.031 & 0.156 & 4 \\
\hline
\end{tabular}

Table 4. Priority ranking of sustainable transport strategies for Tabuk City of the Saudi Arabia 
heterogeneous data coming from multiple stakeholders which is covered in terms of different types of user group in Tabuk City. This methodology can be adopted as a comprehensive and flexible evaluation framework for local assessment conditions used by transportation agencies to examine the conditions of the existing transportation policy or planned transportation strategies for infrastructure and future sustainable transportation developments in country.

\section{Acknowledgements}

The authors acknowledge the funding from University of Tabuk (Saudi Arabia).

\section{References}

Al-Atawi, A.; Saleh, W. 2014. Travel behaviour in Saudi Arabia and the role of social factors, Transport 29(3): 269-277. http://dx.doi.org/10.3846/16484142.2014.913199

Alonso, J. A.; Lamata, M. T. 2006. Consistency in the analytic hierarchy process: a new approach, International Journal of Uncertainty, Fuzziness and Knowledge-Based Systems 14(4): 445-460. http://dx.doi.org/10.1142/S0218488506004114

Awasthi, A.; Chauhan, S. S. 2011. Using AHP and DempsterShafer theory for evaluating sustainable transport solutions, Environmental Modelling \& Software 26(6): 787-796. http://dx.doi.org/10.1016/j.envsoft.2010.11.010

Belton, V.; Gear, T. 1983. On a short-coming of Saaty's method of analytic hierarchies, Omega 11(3): 228-230. http://dx.doi.org/10.1016/0305-0483(83)90047-6

Castillo, H.; Pitfield, D. E. 2010. ELASTIC - a methodological framework for identifying and selecting sustainable transport indicators, Transportation Research Part D: Transport and Environment 15(4): 179-188.

http://dx.doi.org/10.1016/j.trd.2009.09.002

Dyer, J. S.; Wendell, R. E. 1985. A Critique of the Analytic Hierarchy Process. Working Paper, 84/85-4-24. Department of Management, the University of Texas at Austin, Austin, TX.

EIA. 2014. US Energy Information Administration (EIA). Available from Internet: http://www.eia.doe.gov

Goepel, K. D. 2014. BPMSG AHP Online System: Multi-Criteria Decision Making Using the Analytic Hierarchy Process. Available from Internet: http://bpmsg.com/academic/ahp. php

Hull, A. 2008. Policy integration: what will it take to achieve more sustainable transport solutions in cities?, Transport Policy 15(2): 94-103. http://dx.doi.org/10.1016/j.tranpol.2007.10.004

Ibeas, A.; Dell'Olio, L.; Montequín, R. B. 2011. Citizen involvement in promoting sustainable mobility, Journal of Transport Geography 19(4): 475-487. http://dx.doi.org/10.1016/j.jtrangeo.2010.01.005

Kara, Y.; Köne, A. Ç. 2012. The analytic hierarchy process (AHP) approach for assessment of regional environmental sustainability, in Evidence for Sustainable Development: 2012 Berlin Conference on the Human Dimensions of Global Environmental Change, 5-6 October 2012, Berlin, Germany, 1-10.

Ministerio de Planificación y Desarrollo - Alcalá. 2005. Participación ciudadana, planificación y gestión territorial: Análisis teórico conceptual, revisión de experiencias y propuestas de participación para instrumentos específicos. Informe Final. Gobierno de Chile, Santiago. (in Spanish).
Paz, A.; Maheshwari, P.; Kachroo, P.; Ahmad, S. 2013. Estimation of Performance indices for the planning of sustainable transportation systems, Advances in Fuzzy Systems 2013: 1-13. http://dx.doi.org/10.1155/2013/601468

Quddus, M. A.; Oliveira, H. F.; Alecsandru, C. 2014. A framework to assess the sustainability of transportation systems based on analytic hierarchy process, in TRB 93rd Annual Meeting Compendium of Papers, 12-16 January 2014, Washington, DC, 1-21.

Rahman, S. M.; Al-Ahmadi, H. M. 2011. Evaluation of transportation demand management (TDM) strategies and its prospect in Saudi Arabia, Jordan Journal of Civil Engineering 4(2): 170-182.

Rossi, R.; Gastaldi, M.; Gecchele, G. 2013. Comparison of fuzzy-based and AHP methods in sustainability evaluation: a case of traffic pollution-reducing policies, European Transport Research Review 5(1): 11-26. http://dx.doi.org/10.1007/s12544-012-0086-5

Saaty, T. L. 2000. Fundamentals of Decision Making and Priority Theory with the Analytic Hierarchy Process. RWS Publications. $477 \mathrm{p}$.

Saaty, T. L. 1995. Transport planning with multiple criteria: The analytic hierarchy process applications and progress review, Journal of Advanced Transportation 29(1): 81-126. http://dx.doi.org/10.1002/atr.5670290109

Saaty, T. L. 1986. Axiomatic foundation of the analytic hierarchy process, Management Science 32(7): 841-855. http://dx.doi.org/10.1287/mnsc.32.7.841

Saaty, T. L. 1980. The Analytic Hierarchy Process: Planning, Priority Setting, Resource Allocation. Mcgraw-Hill. 287 p.

Saaty, T. L. 1977. A scaling method for priorities in hierarchical structures, Journal of Mathematical Psychology 15(3): 234-281. http://dx.doi.org/10.1016/0022-2496(77)90033-5

Salo, A. A.; Hämäläinen, R. P. 1997. On the measurement of preferences in the analytic hierarchy process, Journal of Multi-Criteria Decision Analysis 6(6): 309-319.

http://dx.doi.org/10.1002/(SICI)1099-1360(199711)6: 6\%3C309::AID-MCDA163\%3E3.0.CO;2-2

Shiau, T.-A. 2012. Evaluating sustainable transport strategies with incomplete information for Taipei City, Transportation Research Part D: Transport and Environment 17(6): 427-432. http://dx.doi.org/10.1016/j.trd.2012.05.002

Tao, C.-C.; Hung, C.-C. 2003. A comparative approach of the quantitative models for sustainable transportation, Journal of the Eastern Asia Society for Transportation Studies 5: 3329-3344.

Triantaphyllou, E.; Mann, S. H. 1995. Using the analytic hierarchy process for decision making in engineering applications: some challenges, International Journal of Industrial Engineering: Applications and Practice 2(1): 35-44.

Yedla, S.; Shrestha, R. M. 2007. Application of Analytic Hierarchy Process to Prioritize Urban Transport Options - Comparative Analysis of Group Aggregation Methods. Indira Gandhi Institute of Development Research, Mumbai, India. $23 \mathrm{p}$. 